\title{
Upgrading Students' Interest melalui Model Pembelajaran Color-Coded Co-op Cards (CoCoCa) di Madrasah Ibtidaiyah
}

\author{
Muhammad Mushfi El Iq Bali ${ }^{1}$, Mahfud Dhofir Jailani ${ }^{2}$, \\ Moh. Nadir Romaodhoni ${ }^{3}$, Ratnawati ${ }^{4}$ \\ Universitas Nurul Jadid Probolinggo \\ mushfieliqbali8@gmail.com
}

\begin{abstract}
Low student interest in learning affects student learning outcomes. Thus, stimulation is needed to increase student interest in learning so that it can improve student learning outcomes. This study aims to determine the application of the Color-Coded Co-op Cards (CoCoCa) learning model in increasing students' interest in learning towards Islamic Education in MI Tarbiyatul Islamiyah Sumberkerang Gending Probolinggo and its supporting and inhibiting factors. This study uses a qualitative research approach. The type used in this research is a case study. The results of the study are based on data exposure and interview results, the Color-Coded Co-op Cards (CoCoCa) learning model is very suitable to be applied in MI Tarbiyatul Islamiyah Sumberkerang Gending Probolingoo the Color-Coded Co-op Cards $(\mathrm{CoCoCa})$ cooperative learning model is able to create an atmosphere and learning conditions that are pleasant and not saturating. This is different from the findings in the observation results, when the teacher uses the lecture method, the majority of students feel boredom so that students passively participate in learning and even fall asleep in the classroom. However, when the teacher applies the Color-Coded Co-op Cards (CoCoCa) learning model, it is known that the percentage of student interest in learning increases by up to $85 \%$ to be more active in learning compared to other learning model.
\end{abstract}

Keywords: Learning Interest, Color-Coded Co-op Cards (CoCoCa), Madrasah Ibtidaiyah

\begin{abstract}
Abstrak : Rendahnya minat belajar siswa berpengaruh terhadap hasil belajar siswa tersebut. Dengan demikian, diperlukan rangsangan untuk meningkatkan minat belajar siswa sehingga dapat meningkatkan hasil belajar siswa. Penelitian ini bertujuan untuk mengetahui penerapan model pembelajaran Color-Coded Co-op Cards (CoCoCa) dalam meningkatkan minat belajar siswa terhadap mata pelajaran PAI di MI Tarbiyatul Islamiyah Sumberkerang Gending Probolinggo serta faktor pendukung dan penghambatnya. Penelitian ini menggunakan pendekatan penelitian kualitatif. Jenis yang digunakan dalam penelitian ini studi kasus. Hasil penelitian berdasarkan paparan data dan hasil wawancara, model pembelajaran Color-Coded Co-op Cards (CoCoCa) sangatlah sesuai untuk diterapkan di MI Tarbiyatul Islamiyah Sumberkerang Gending Probolinggo model pembelajaran kooperatif Color-Coded Co-op Cards (CoCoCa) mampu menciptakan suasana dan kondisi pembelajaran yang menyenangkan dan tidak menjenuhkan. Hal ini berbeda dengan temuan pada hasil observasi, ketika guru menggunakan metode ceramah, mayoritas siswa merasakan kejenuhan sehingga siswa pasif mengikuti pembelajaran bahkan tertidur di dalam kelas. Namun saat guru menerapkan model pembelajaran Color-Coded Co-op Cards (CoCoCa), diketahui persentase minat belajar siswa meningkat hingga $85 \%$ lebih aktif dalam pembelajaran dibandingkan dengan model pembelajaran yang lain.
\end{abstract}

Kata Kunci: Minat Belajar, Color-Coded Co-op Cards (CoCoCa), Madrasah Ibtidaiyah

MANAZHIM : Jurnal Manajemen dan Ilmu Pendidikan

Volume 3, Nomor 2, Agustus 2021; 151-170

https:// ejournal.stitpn.ac.id/index.php/manazhim 


\section{PENDAHULUAN}

Pendidikan merupakan suatu proses yang strategis dalam mencerdaskan kehidupan bangsa, sehingga pengelolaan pendidikan harus dilakukan secara profesional. Pendidikan memiliki keterkaitan yang cukup erat dengan sekolah, dimana sekolah sebagai wadah untuk melaksanakan proses pendidikan. Di sekolah sendiri juga memberikan tingkatan-tingkatan kelas. Tingkatan-tingkatan kelas didasarkan pada tahap perkembangan siswa. Perkembangan ini dapat dilihat dari setiap aspek yang dimiliki oleh siswa tersebut, yang meliputi aspek kognitif, afektif, dan psikomotorik. Dalam hal ini aspek kognitif menekankan pada pengetahuan siswa, afektif berkaitan dengan sikap siswa baik dalam mengikuti pelajaran maupun keadaan siswa di lingkungan sekolah dan aspek psikomotorik menekankan pada keterampilan dan kemampuan bertindak pada masing-masing siswa. ${ }^{1}$ Given the importance of education in an effort to uplift dignity and prepare humans who have intellect, spirituality and good morals, this kind of education requires a hard and serious effort and thought in an effort to realize his goals. ${ }^{2}$

Di lingkungan sekolah kegiatan belajar merupakan kegiatan yang paling pokok. Hal ini menandakan bahwa berhasil tidaknya pencapaian tujuan pendidikan dipengaruhi kepada pembelajaran yang dilakukan oleh guru untuk membangun minat belajar siswa. ${ }^{3}$ Keberhasilan belajar siswa salah satunya dipengaruhi oleh keterlibatan guru dalam kegiatan pembelajaran. Guru memegang peran yang sangat penting dalam kegiatan belajar mengajar. Tugas guru sebagai profesi meliputi mendidik, mengajar, dan melatih. Educating means passing on and developing the values of life. Teaching means continuing and developing science and technology. Meanwhile, training means developing skills in students. ${ }^{4}$ Di sekolah, guru berperan sebagai komponen manusiawi yang menggerakkan proses pembelajaran secara aktif mengupayakan pembentukan sumber daya manusia yang potensial membangun peradaban.

\footnotetext{
${ }^{1}$ Miftahul Huda, “Cooperative Learning”, (Yogyakarta: Pustaka Pelajar, 2012)

2 Muhammad Mushfi El Iq Bali and Devi Ruzifah, "Mitigation of Student Deviant Behaviour through Al-Ghazali's Perspective Spiritual Values in the Disruptive Era," Jurnal Pendidikan Progresif 11, no. 1 (2021): 63-76, https://doi.org/10.23960/jpp.v11.i1.20210.

3 Hasan Baharun et al., "Self-Efficacy Sebagai Media Peningkatan Profesionalisme Guru Di Madrasah," Risalah: Jurnal Pendidikan Dan Studi Islam 6, no. 1 (2020): 244-57.

4 Abd Hamid Wahid et al., "Effectiveness of Android-Based Mathematics Learning Media Application on Student Learning Achievement," in Journal of Physics: Conference Series (IOP Publishing, 2020), 1-7, https://doi.org/10.1088/1742-6596/1594/1/012047.
} 
Kegairahan belajar yang tinggi, semangat belajar yang menggebu dan rasa percaya diri juga dapat mempengaruhi keberhasilan pembelajaran. Berdasarkan hal ini, peranan guru sangat diperlukan untuk meningkatkan minat belajar siswa. Minat siswa dalam belajar sangatlah berpegaruh dalam kemampuan siswa untuk menangkap materi yang disampaikan guru. If the learning material does not match the student's interest, the student will not learn as well as he can because there is no attraction for bim. ${ }^{5}$ Dengan demikian, minat belajar juga akan mempengaruhi proses belajar mengajar. Untuk itu, maka diperlukan strategi belajar mengajar yang baik sehingga dapat meningkatkan minat siswa dalam belajar.

Kurangnya minat siswa tersebut berpengaruh juga terhadap hasil belajar siswa. Berdasarkan hasil ulangan Pendidikan Agama Islam siswa, hanya ada 25,64\% siswa yang dapat memperoleh nilai di atas rata-rata kelas (80). Sedangkan 74,36\% siswa masih belum dapat mencapai nilai rata-rata kelas. Dari data tersebut dapat diketahui bahwa siswa memiliki hasil belajar yang rendah. Dengan demikian, diperlukan rangsangan untuk meningkatkan minat belajar siswa sehingga dapat meningkatkan hasil belajar siswa. Minat adalah faktor internal yang sangat mempengaruhi keberhasilan belajar siswa. ${ }^{6}$ Secara umum pengertian minat adalah kecenderungan yang tetap untuk memperhatikan dan mengenang beberapa kegiatan, kegiatan yang diminati seseorang, diperhatikan terus-menerus yang disertai dengan rasa senang.

Dari penjelasan ini, peneliti mengaitkan dengan apa yang terjadi dalam pembelajaran. Siswa seringkali tidak semangat dalam belajar, entah itu disebabkan karena siswa tidak suka dengan mata pelajarannya atau tidak suka dengan gaya ajar seorang gurunya ataupun juga disebabkan faktor lainnya. Dalam hal seperti ini, agar seorang siswa memperhatikan dan berminat belajar, guru sering kali masih menyuruh atau membuat dorongan agar siswanya berminat dalam pembelajaran.

5 Dewi Oktavia et al., "Exploration of Fine Motor Skills through the Application of Paint," in WESTECH (European Alliance for Innovation n.o., 2019), 1-6, https://doi.org/10.4108/eai.8-122018.2284038.

${ }^{6}$ Muhammad Mushfi El Iq Bali and Moh. Fajar Sodik Fadli, "Implementasi Nilai-Nilai Pendidikan Pesantren Dalam Meningkatkan Ketahanan Mental Santri," PALAPA: Jurnal Studi Keislaman Dan Ilmu Pendidikan 7, no. 1 (May 21, 2019): 1-15, https://doi.org/10.36088/palapa.v7i1.164. 
Kenyataan di lapangan banyak dijumpai siswa belajar karena terpaksa atau karena kewajiban bukan karena kebutuhan, khususnya di MI Tarbiyatul Islamiyah Sumberkerang Gending Probolinggo. Sehingga mereka melakukan kegiatan belajar tidak dengan sepenuh hati atau asal-asalan saja sehingga hasil yang diperoleh tidak optimal. Padahal, motivasi merupakan salah satu faktor yang mempengaruhi keberhasilan belajar murid. High learning motivation is one of the determinants of student success in achieving the best learning outcomes. ${ }^{7}$ Hal tersebut terjadi karena didasari tidak adanya motivasi dan kemauan yang tulus dalam diri seorang siswa, lemahnya motivasi siswa tersebut dalam belajar sehingga yang ada dalam dirinya hanya malas dan tidak ada semangat. Disamping itu pula, seorang pendidik atau guru dituntut memiliki kemampuan professional, artinya baik dalam motivasi untuk mengajar maupun kemampuan secara teknis instruksional, guru tersebut benar-benar dapat diandalkan. Namun, guru masih sering menggunakan metode konservatif atau ceramah, yang berakibat siswa bosan dan kurang semangat dalam pembelajaran.

Salah satu bentuk profesionalitas seorang guru adalah jika yang bersangkutan mampu menerapkan model pembelajaran yang baik, salah satunya adalah model pembelajaran kooperatif. Mastery of learning methods, tools/media and techniques must be applied and reflected in the learning program. ${ }^{8}$ Jadi, proses pembelajaran harus bervariatif, metode yang digunakan tidak monoton, sehingga potensi yang ada pada masingmasing anak dapat dikembangkan secara optimal.

Pembelajaran kooperatif merujuk pada berbagai macam metode pengajaran dimana para siswa bekerja dalam kelompok-kelompok kecil untuk saling membantu dalam mempelajari materi pelajaran menutup kesenjangan dalam pemahaman masing-masing. The reason for using cooperative learning is to increase student achievement and to grow awareness that students need to learn to think, solve problems, and integrate and apply their skills and knowledge. ${ }^{9}$ Pembelajaran kooperatif merupakan sarana yang sangat baik

${ }^{7}$ Syaiful Islam et al., "To Boost Students' Motivation and Achievement through Blended Learning," in Journal of Physics: Conference Series, vol. 1114 (Institute of Physics Publishing, 2018), 1-11, https://doi.org/10.1088/1742-6596/1114/1/012046.

${ }^{8}$ Muhammad Mushfi El Iq Bali and Musrifah, "The Problems of Application of Online Learning in the Affective and Psychomotor Domains During the Covid-19 Pandemic," Jurnal Pendidikan Agama Islam 17, no. 2 (2020): 137-54, https://doi.org/https://doi.org/10.14421/jpai.2020.172-03.

9 Spencer Kagan and Miguel Kagan, Kagan Cooperative Learning, Kagan (San Clemente: Kagan Publishing, 2009). 
untuk mencapai hal-hal semacam itu. Model pembelajaran kooperatif sendiri sudah semakin berkembang dengan berbagai tipe. Untuk mengatasi permasalahan dalam pembelajaran tersebut, guru PAI MI Tarbiyatul Islamiyah Sumberkerang Gending Probolinggo memilih untuk menggunakan model pembelajaran kooperatif tipe kooperatif Color-Coded Co-op Cards (CoCoCa) untuk meningkatkan minat belajar siswa dalam mempelajari mata pelajaran Pendidikan Agama Islam di MI Tarbiyatul Islamiyah Sumberkerang Gending Probolinggo Berdasarkan hasil penelitian terdahulu, diantara beberapa model pembelajaran kooperatif tersebut, tipe Color-Coded Co-op Cards (CoCoCa) memiliki tingkat keberhasilan yang tinggi karena tipe ini memiliki karakter yang dapat memberikan ruang gerak bagi siswa untuk berinteraksi dengan sesama siswa di dalam kelas. ${ }^{10}$ Di samping itu juga penerapan model pembelajaran kooperatif Color-Coded Co-op Cards (CoCoCa) ini membuat pembelajaran semakin kreatif dan menarik. Dengan adanya interaksi antar siswa dapat mengurangi rasa bosan siswa ketika belajar di dalam kelas dan minat siswa untuk belajar juga semakin tinggi.

\section{Model Pembelajaran Color-Coded Co-op Cards (CoCoCa)}

Model pembelajaran Color-Coded Co-op Cards (CoCoCa) merupakan model pembelajaran kooperatif yang digunakan untuk membangkitkan aktivitas siswa belajar dan cocok digunakan dalam bentuk permainan. Model Pembelajaran Color-Coded Coop Cards (CoCoCa) dikembangkan oleh Spencer Kagan. The use of this model leads students to find a partner while learning a particular concept or topic in a fun atmosphere. ${ }^{11}$ Model pembelajaran ini dapat diterapkan untuk semua mata pelajaran salah satunya mata pelajaran Pendidikan Agama Islam dan untuk semua tingkatan kelas. Berikut langkahlangkah model pembelajaran Color-Coded Co-op Cards (CoCoCa).

Tabel 1. Sintaks Color-Coded Co-op Cards (CoCoCa)

\begin{tabular}{lll}
\hline 1 & Pretest. & Semua siswa mengerjakan pretest. \\
\hline 2 & $\begin{array}{l}\text { Students Create Color }- \\
\text { Coded Co-op Cards. }\end{array}$ & Setiap siswa dalam tim membuat satu set kartu dengan \\
& warna yang berbeda pada butir soal yang terlewat saat \\
& pretest. Jika siswa tidak melewatkan butir soal, mereka \\
\hline
\end{tabular}

10 Agus Suprijono, "Cooperative Learning: Teori dan Aplikasi PAIKEM", (Yogyakarta: Pustaka Pelajar, 2012).

${ }^{11}$ Kagan and Kagan. 


\begin{tabular}{|c|c|c|}
\hline & & membuat kartu dari kumpulan pertanyaan tantangan. \\
\hline 3 & $\begin{array}{l}\text { Students Play the Flashcard } \\
\text { Game. }\end{array}$ & $\begin{array}{l}\text { Siswa memenangkan kembali kartu yang mereka kuasai } \\
\text { melalui tiga putaran Game Flashcard. }\end{array}$ \\
\hline 4 & Practice Test. & $\begin{array}{l}\text { Setelah Game Flashcard, siswa mengikuti tes latihan } \\
\text { pada semua item. }\end{array}$ \\
\hline 5 & $\begin{array}{l}\text { Initial Color-Coded } \\
\text { Improvement Scoring. }\end{array}$ & $\begin{array}{l}\text { Rekan tim menempatkan bintang di Flashcard yang } \\
\text { mereka jawab dengan benar pada tes latihan, lalu } \\
\text { mengumpulkan dan menghitung kartu berbintang } \\
\text { untuk tim merayakan keberhasilan mereka. }\end{array}$ \\
\hline 6 & $\begin{array}{l}\text { Repeated Practice on Missed } \\
\text { Items. }\end{array}$ & $\begin{array}{l}\text { Game Flashcard dimainkan lagi pada semua item yang } \\
\text { terlewat pada pretest. Untuk beberapa siswa, mengikuti } \\
\text { tes latihan akan ada kebutuhan untuk meningkatkan } \\
\text { tumpukan kartu mereka. }\end{array}$ \\
\hline 8 & $\begin{array}{l}\text { Final Test and Final } \\
\text { Improvement Scoring. }\end{array}$ & $\begin{array}{l}\text { Siswa mengambil tes akhir, memberi bintang pada } \\
\text { semua kartu yang mereka jawab dengan benar pada tes } \\
\text { akhir, mengumpulkan kartu yang berbintang, dan } \\
\text { menghitungnya untuk menentukan skor peningkatan } \\
\text { akhir untuk tim. }\end{array}$ \\
\hline 9 & $\begin{array}{l}\text { Individual, Team, } \\
\text { and Class Recognition. }\end{array}$ & $\begin{array}{l}\text { Individu dan Tim dapat memposting dan } \\
\text { mengumumkan skor peningkatan mereka pada grafik } \\
\text { skor peningkatan individu dan tim. Siswa dan tim } \\
\text { dengan peningkatan yang lebih besar dari minggu } \\
\text { sebelumnya, atau pada tingkat tertentu, dapat diminta } \\
\text { untuk berdiri, bersorak atau berjabat tangan, dan } \\
\text { dikenali oleh kelas. }\end{array}$ \\
\hline 10 & Reflection. & $\begin{array}{l}\text { Siswa diberi waktu untuk mendiskusikan bagaimana } \\
\text { mereka dapat membantu pasangannya dengan sebaik- } \\
\text { baiknya saat bermain Game Flashcard. }\end{array}$ \\
\hline
\end{tabular}

Penerapan model pembelajaran kooperatif tipe Color-Coded Co-op Cards (CoCoCa) ini memiliki beberapa keunggulan, yaitu: (a) Siswa dapat belajar sambil mempelajari sesuatu konsep atau topik, (b) Kegiatan dengan menggunakan model Color-Coded Co-op Cards (CoCoCa) dapat menimbulkan suasana yang menyenangkan karena memiliki unsur permainan, (c) Dapat diterapkan untuk semua mata pelajaran 
dan tingkat-tingkatan kelas, (d) Melatih kerja sama dan meningkatkan aktivitas siswa, dan (e) Efektif melatih kedisiplinan siswa menghargai waktu belajar. ${ }^{12}$

Di samping keunggulan tersebut model pembelajaran kooperatif tipe ColorCoded Co-op Cards (CoCoCa) ini juga memiliki beberapa kelemahan, seperti; (a) Jika strategi pembelajaran tidak dipersiapkan dengan baik, akan membuang banyak waktu, (b) Akan ada siswa yang malu ketika mendapat pasangan yang berlawanan jenis, (c) Jika guru tidak mengarahkan siswa dengan baik, akan banyak siswa yang kurang memperhatikan saat teman yang lain presentasi, dan (d) Guru harus bijak apabila terdapat siswa yang tidak mendapat pasangan. ${ }^{13}$

\section{Students' Interest}

Minat adalah kecenderungan dan kegairahan yang tinggi atau keinginan yang besar terhadap sesuatu. Interest can affect the quality of achievement of student learning outcomes in certain fields of study. ${ }^{14}$ Minat merupakan rasa ketertarikan terhadap suatu hal ataupun aktifitas yang muncul dari dalam diri siswa. Adanya minat dalam diri siswa untuk belajar dapat memberikan pengaruh terhadap keberhasilan siswa dalam belajar. Minat yang timbul bersumber dari pengenalan dengan lingkungan atau hasil berinteraksi dan belajar dengan lingkungan. ${ }^{15}$ Adapun minat belajar yang dimaksud dalam penelitian ini ialah rasa ketertarikan atau rasa suka siswa di MI Tarbiyatul Islamiyah Sumberkerang Gending Probolinggo terhadap pembelajaran Pendidikan Agama Islam.

Unsur yang terkandung di dalam minat antara lain, adanya: (a) Suatu gejala psikologis, (b) Pemusatan perhatian, perasaan dan pikiran dari subyek karena tertarik, (c) Perasaan senang terhadap obyek menjadi sasaran, dan (d) Kemauan atau

\footnotetext{
12 Muhammad Mushfi El Iq Bali, Nurul Hidayah, and Siti Maisyaro AL, STRATEGI PEMBELAJARAN Pendidikan Agama Islam, Pustaka Nurja, vol. 1 (Probolinggo: Pustaka Nurja, 2018), https://lp3m.unuja.ac.id/bas/strategi-pembelajaran-pendidikan-agama-islam.html.

13 Anita Lie, "Mempraktikkan Cooperative Learning di Ruang-Ruang Kelas", (Jakarta: Grasindo, 2010)

14 Fathor Rozi et al., "Learning Management; Identifying Learning Styles of Language Learners in Madrasah," Proceedings of the International Conference on Industrial Engineering and Operations Management 5, no. August (2020): 3783-90.

15 Muhammad Mushfi El Iq Bali and Itatul Masulah, "Hypnoteaching: Solusi Siswa Learning Disorder," At-Turats: Jurnal Pemikiran Pendidikan Islam 13, no. 1 (2019): 89-103, https://doi.org/10.24260/at-turats.v13i1.1188.
} 
kecenderungan pada diri subyek untuk melakukan kegiatan guna mencapai tujuan. ${ }^{16}$ (Khairani, 2013). Dari yang telah diungkapkan mengenai unsur-unsur yang terkandung dalam minat salah satunya adalah adanya perasaan senang terhadap suatu obyek. Perasaan senang tersebut yang mendasari peneliti dalam penelitian ini untuk membangkitkan minat siswa. Efforts that can be made to foster children's interest to be more productive and effective include: (a) Enriching ideas or ideas, (b) Giving stimulating gifts, (c) Getting to know creative people, (d) Adventure in the sense of adventure to the natural surroundings in a bealthy manner, (e) Developing fantasies, (f) Practicing a positive attitude. ${ }^{17}$

Dalam pembelajaran Pendidikan Agama Islam, penguasaan guru akan materi dan pemahaman dalam memilih model pembelajaran yang tepat untuk materi tersebut akan sangat menentukan keberhasilan pencapaian tujuan pembelajaran. Salah satu model pembelajaran yang saat ini dianggap tepat dalam pembelajaran Pendidikan Agama Islam adalah melalui model pembelajaan Color-Coded Co-op Cards (CoCoCa). Minat belajar siswa dapat meningkat melalui penerapan model tersebut sehingga hasil belajar siswa juga meningkat dengan signifikan. Model pembelajaran Color-Coded Co-op Cards (CoCoCa) dalam pembelajaran Pendidikan Agama Islam dipandang tepat sekali yang meliputi 3 langkah pengajaran PAI karena sesuai dengan model pembelajaran Color-Coded Co-op Cards (CoCoCa) yaitu menata nilai, menata ruang kelas, dan memperhatikan proses pembelajaran. Dimana guru dapat menyampaikan materi pembelajaran di kelas secara inovatif dengan mengkombinasikan model maupun strategi pembelajaran secara tepat sehingga siswa dapat meningkatkan minat belajar melalui pembelajaran dengan menyenangkan dan pembelajaran dapat berjalan efektif dan efisien.

\footnotetext{
${ }^{16}$ Khairani, "Psikologi Belajar", (Yogyakarta: Aswaja Pressindo, 2013).

17 Muhammad Mushfi El Iq Bali and Noer Holilah, "The Role of Foster Caregivers in the Effectiveness of Online Learning in Pesantren," Edukasi Islami: Jurnal Pendidikan Islam 10, no. 1 (2021): 339-62.
} 


\section{METODE PENELITIAN}

Pendekatan penelitian ini menggunakan pendekatan penelitian kualitatif. Jenis penelitian ini adalah studi kasus. Peneliti memilih penelitian studi kasus karena penelitian studi kasus berusaha menggambarkan kehidupan dan tindakan-tindakan manusia secara khusus pada lokasi tertentu dengan kasus tertentu. Lokasi penelitian di MI Tarbiyatul Islamiyah Sumberkerang Gending Probolinggo. Tahapan penelitian meliputi; (a) Tahap pendahuluan (observasi), (b) Tahap pelaksanaan (pengumpulan data), (c) Tahap analisis data, dan (d) Tahap pelaporan.

Kedudukan peneliti dalam penelitian ini adalah sebagai instrumen utama. Selain itu peneliti juga sebagai perencana, pelaksana pengumpulan data, analisis, penafsir data, dan pada akhirnya ia menjadi pelapor hasil penelitiannya. Data primer dalam penelitian ini adalah Kepala Sekolah, guru Pendidikan Agama Islam, dan siswa MI Tarbiyatul Islamiyah Sumberkerang Gending Probolinggo. Sedangkan data sekunder berupa dokumen dan arsip yang menunjang data penelitian. Teknik pengumpulan data meliputi; observasi, dokumentasi, dan wawancara. Informan penelitian ini yaitu; Kepala Sekolah, Waka Kurikulum, guru, dan siswa MI Tarbiyatul Islamiyah Sumberkerang Gending Probolinggo.

Teknik analisis data menggunakan tiga komponen, yaitu; reduksi data (data reduction), penyajian data (data display), dan penarikan kesimpulan (conclution drowing/verification). Pengecekan keabsahan data dalam penelitian ini melalui; (a) Observasi yang dilakukan secara terus menerus (persistent observation), (b) Trianggulasi data, (c) Diskusi teman sejawat (reviewing), dan (d) Pengecekan mengenai ketercukupan referensi (referential adequacy check).

\section{HASIL DAN PEMBAHASAN}

Upgrading Students' Interest melalui Model Pembelajaran Color-Coded Coop Cards (CoCoCa) di Madrasah Ibtidaiyah

a. Persiapan Mengajar dengan Model Pembelajaran Color-Coded Co-op Cards $(\mathrm{CoCoCa})$ 
Ada beberapa kemampuan dan sikap yang harus dimiliki guru dalam melaksanakan tugasnya:

1. Menyiapkan RPP

Guru yang baik adalah guru yang mempersiapkan rencana pelaksanaan pembelajaran (RPP) sebelum ia mengajar. RPP ini berfungsi sebagai skenario proses pembelajaran agar lebih mempermudah, dan menciptakan kegiatan pembelajaran yang lebih terarah pada tujuan pembelajaran. "Dalam pembuatan RPP tidak bisa sembarangan, semuanya harus tersusun dengan rapi dan harus sesuai dengan standar kompetisi, kompetensi dasar serta tujuan pembelajaran yang akan dicapai, sehingga diharapkan pembelajaran akan berjalan dengan lancar lebih efektif dan efesien (Sahri, Wawancara pribadi, 12 Januari 2021).”

2. Mempersiapkan Materi Pembelajaran

Guru professional adalah guru yang memiliki kompetensi dan kualifikasi yang sesuai dengan jenjang profesinya. Hal kecil pun juga perlu dilakukan untuk membuat pembelajaran berjalan dengan baik, baik itu yang bersifat persiapan ataupun saat pembelajaran, dan salah satu yang paling penting adalah mempersiapkan mata pelajaran yang akan diajarkan. Merangkai pembelajaran yang akan diajarkan merupakan usaha guru untuk membuat siswa tidak jenuh dalam pembelajaran. "Guru dan karyawan yang profesional sangatlah mendukung tercapainya proses pendidikan di MI Tarbiyatul Islamiyah Sumberkerang Gending Probolinggo, karena percuma di wilayah mereka disuruh ke sekolah tapi sampai di sekolah tidak ada gurunya. Jadi, guru dan karyawan di MI Tarbiyatul Islamiyah Sumberkerang Gending Probolinggo ini harus profesional dalam bidangnya masing-masing (Sahri, Wawancara pribadi, 12 Januari 2021).”

3. Menyiapkan Media Pembelajaran Model Kooperatif Color-Coded Co-op Cards $(\mathrm{CoCoCa})$

Dalam pelaksanaan pembelajaran yang menggunakan model pembelajaran Color-Coded Co-op Cards ( $\mathrm{CoCoCa}$ ) ada beberapa yang harus 
diperhatikan oleh seorang pendidik, yang pertama menyiapkan kartu permainan. Kartu-kartu tersebut terdiri dari kartu berisi pertanyaanpertanyaan sesuai materi yang akan diajarkan.

4. Menguasai Materi

Sebagai pengajar, guru hendaknya menguasai bahan atau materi pelajaranya akan diajarkan serta senantiasa mengebangkan dan meningkatkan kemampuannya. Karena itu sebenarnya guru sendiri adalah seorang pelajar yang belajar secara terus menerus. "Guru adalah tempat menimba ilmu bagi para siswanya, selain itu guru juga sebagai pengajar ia harus membantu perkembangan anak didiknya untuk memahami, dan menguasai ilmu pengetahuan (Sahri, Wawancara pribadi, 12 Januari 2021).”

5. Menguasai Metode dan Teknik Penilaian

Seorang guru akan dapat melaksanakan tugasnya dengan baik bila ia menguasai dan mampu melaksanakan keterampilan mengajar dengan menggunakan metode yang sesuai dengan pelajaran, tujuan dan pokok bahasan yang diajarkannya. Bahan ajar yang telah dikuasainya belum tentu dapat dicerna oleh siswa bila tidak disampaikan dengan baik. Proses penyampaian ini memerlukan kecakapan khusus. Dengan demikian, perlu penguasaan guru terhadap metode penyampaian agar para siswa tidak pasif, melainkan terlibat secara aktif dalam onteraksi belajar mengajar. Penilaian merupakan bagian yang tak terpisahkan dari proses belajar mengajar. "Penilaian bertujuan untuk memberikan umpan balik bagi guru dalam merencanakan dan melaksanakan kegiatan belajar mengajar maupun bagi siswa sendiri dan orang tua siswa, penilaiaan bermanfaat untuk mengetahui kemajuan belajar siswa (Sahri, Wawancara pribadi, 12 Januari 2021).”

b. Pelaksanaan Model Pembelajaran Color-Coded Co-op Cards (CoCoCa)

Dalam penerapan model pembelajaran Color-Coded Co-op Cards (CoCoCa) di MI Tarbiyatul Islamiyah Sumberkerang Gending Probolinggo yaitu dengan langkah-langkah sebagai berikut: “(1) Semua siswa mengerjakan pretest. (2) Setiap siswa dalam tim membuat satu set kartu dengan warna yang berbeda pada 
butir soal yang terlewat saat pretest. Jika siswa tidak melewatkan butir soal, mereka membuat kartu dari kumpulan pertanyaan tantangan. (3) Siswa memenangkan kembali kartu yang mereka kuasai melalui tiga putaran Game Flashcard. (4) Setelah Game Flashcard, siswa mengikuti tes latihan pada semua item. (5) Rekan tim menempatkan bintang di Flashcard yang mereka jawab dengan benar pada tes latihan, lalu mengumpulkan dan menghitung kartu berbintang untuk tim merayakan keberhasilan mereka. (6) Game Flashcard dimainkan lagi pada semua item yang terlewat pada pretest. Untuk beberapa siswa, mengikuti tes latihan akan ada kebutuhan untuk meningkatkan tumpukan kartu mereka. (7 \& 8) Siswa mengambil tes akhir, memberi bintang pada semua kartu yang mereka jawab dengan benar pada tes akhir, mengumpulkan kartu yang berbintang, dan menghitungnya untuk menentukan skor peningkatan akhir untuk tim. (9) Individu dan Tim dapat memposting dan mengumumkan skor peningkatan mereka pada grafik skor peningkatan individu dan tim. Siswa dan tim dengan peningkatan yang lebih besar dari minggu sebelumnya, atau pada tingkat tertentu, dapat diminta untuk berdiri, bersorak atau berjabat tangan, dan dikenali oleh kelas. (10) Siswa diberi waktu untuk mendiskusikan bagaimana mereka dapat membantu pasangannya dengan sebaik-baiknya saat bermain Game Flashcard (Hasan, Wawancara pribadi, 14 Januari 2021).

c. Pasca Pembelajaran Model Koopertaif Color-Coded Co-op Cards (CoCoCa)

1. Evaluasi

Setelah pembelajaran yang menggunakan model pembelajaran kooperatif tipe Color-Coded Co-op Cards (CoCoCa) ini perlu adanya evaluasi yang mana hal ini ditujukan untuk mendapatkan data pembuktian yang akan menunjukkan sampai dimana pencapaian tingkat kemampuan dan keberhasilan siswa dalam mengikuti pembelajaran. Di samping itu juga dapat digunakan oleh guru untuk mengukur atau menilai sampai dimana keefektifan dalam mengajar, dan metode mengajar yang digunakan. "Dalam proses belajar mengajar sangat perlu sekali adanya evaluasi, salah satunya agar seorang pedidik mengetahui sampai dimana tingkat pengetahuan seorang siswanya (Sahri, Wawancara pribadi, 19 Januari 2021).” 
2. Ulangan Harian

Disini tidak cukup hanya mengevaluasi saja, untuk mengetahui sampai dimana pencapaian dalam pembelajaran. Agar lebih efektif selanjutnya disini seorang pendidik memberikan Tes atau Ulangan harian, yang mana tidak lain ditujukan agar mengetahui sampai dimana tingkat pencapaian pemahaman atau keberhasilan siswa dalam pembelajaran. "Salah satu cara yang paling sering digunakan oleh seorang pendidik untuk mengetahui tingkat kemampuan peserta didiknya ialah dengan mengadakan tes atau ujian (Hasan, Wawancara pribadi, 14 Januari 2021)."

Hal ini didukung dengan pernyataan Waka. Kurikulum MI Tarbiyatul Islamiyah Sumberkerang Gending Probolinggo “Ada berbagai macam cara untuk mengetahui tingkat kemampuan peserta didik/siswa, seperti ulangan harian, ulangan semester, ataupun seorang guru langsung bertanya kepada siswanya (Sahri, Wawancara pribadi, 19 Januari 2021)."

3. Minat Belajar Siswa setelah Mengikuti Pembelajaran dengan Menggunakan Model Pembelajaran Color-Coded Co-op Cards (CoCoCa)

Banyak sekali perubahan yang terjadi pada saat dan sebelum sebelum pemebelajaran menggunakan menggunakan model pembelajaran Color-Coded Co-op Cards ( $\mathrm{CoCoCa}$ ). Yang mana perubahan itu paling banyak berdampak positif terhadap kegiatan belajar mengajar. "Dengan menerapkan model pembelajaran Color-Coded Co-op Cards (CoCoCa) ini siswa lebih aktif dalam belajar, yang dulunya sering tidur di kelas sekarang sudah tidak ada yang tidur (Sahri, Wawancara pribadi, 21 Januari 2021).”

Senada dengan yang disampaikan guru mata pelajaran PAI "Ternyata dengan menggunakan model pembelajaran Color-Coded Co-op Cards (CoCoCa) ini siswa lebih antusias dalam belajar, sehingga kegiatan belajar mengajar lebih kondusif dan tidak membosankan (Hasan, Wawancara pribadi, 21 Januari 2021).”

Begitupun yang disampaikan siswa MI Tarbiyatul Islamiyah Sumberkerang Gending Probolinggo "Ketika guru mengajar seperti orang 
ceramah, kami merasa bosan dan ngantuk, tapi akhir-akhir ini pak guru membentuk kelompok untuk kami, jadi kami lebih nyaman dalam belajar, bisa bertukar pikiran dengan teman-teman (Zainal, Wawancara pribadi, 21 Januari 2021).” Selain itu, diperkuat oleh salah satu siswa MI Tarbiyatul Islamiyah Sumberkerang Gending Probolinggo. "Lebih enak belajar dengan kelompok, jadi kalau ada materi yang saya tidak mengerti bisa langsung tanya ke teman, karena kalau bertanya kepada guru saya merasa malu (Anwar, Wawancara pribadi, 21 Januari 2021).”

\section{Faktor Pendukung dan Penghambat Upgrading Students' Interest melalui Model Pembelajaran Color-Coded Co-op Cards (CoCoCa) di Madrasah \\ Ibtidaiyah}

Implementasi model pembelajaran Color-Coded Co-op Cards (CoCoCa) dalam pembelajaran PAI di MI Tarbiyatul Islamiyah Sumberkerang Gending Probolinggo menurut peneliti sangat baik dan sesuai dengan unsur-unsur model cooperative learning. Meskipun dalam pelaksanaannya masih terdapat beberapa kekurangan, akan tetapi langkah menuju kesempurnaan tetap terus diupayakan dengan memaksimalkan faktor penunjang dan meminimalisir faktor penghambat.

Dalam pengamatan peneliti, faktor-faktor yang menunjang keberhasilan penerapan model pembelajaran Color-Coded Co-op Cards (CoCoCa) dalam pembelajaran PAI di MI Tarbiyatul Islamiyah Sumberkerang Gending Probolinggo meliputi: pertama, Guru. Profesionalitas guru merupakan salah satu hal yang menunjang keberhasilan penerapan pengolahan kelas di MI Tarbiyatul Islamiyah Sumberkerang Gending Probolinggo Profesionalitas ini terwujud dalam persiapan baik berupa pemilihan materi ataupun pembentukan kelompok yang dilakukan guru untuk menerapkan model pembelajaran Color-Coded Co-op Cards (CoCoCa). Tanpa adanya persiapan yang sungguh-sungguh atau model pembelajaran tersebut dilaksanakan secara asal-asalan, tentunya tujuan pembelajaran akan sulit tercapai. "Guru dan karyawan yang profesional sangatlah mendukung tercapainya proses pendidikan di SMP Nurul Jadid, karna percuma di wilayah mereka di suruh ke sekolah tapi sampai di sekolah tidak ada gurunya. Jadi guru dan karyawan di SMP ini harus profesional dalam bidangnya masing-masing (Sahri, Wawancara pribadi, 24 Januari 2021).” Hal 
yang sama juga dijelaskan oleh guru mata pelajaran PAI bahwa "Guru yang profesional, jadi kalau sudah masuk dalam kategori guru yayasan maka bagai manapun bentuk tanggung jawabnya maka mau tidak mau terlibat karena itu termasuk dalam integritas sekolah yang mana guru dan karyawan haruslah profesional dan konsisten (Hasan, Wawancara pribadi, 24 Januari 2021).”

Kedua, Siswa. Antusiasme dan rasa ingin tahu yang tinggi dari para siswa merupakan faktor penunjang pelaksanaan model pembelajaran Color-Coded Co-op Cards ( $\mathrm{CoCo} \mathrm{Ca}$ ). Ini terlihat manakala mereka diberi tugas untuk dikerjakan bersamasama dengan mengedepankan unsur gotong-royong ataupun semangat mereka untuk tampil menjadi kelompok yang terbaik dalam setiap presentasi kelompok di depan kelas. Hal ini juga terlihat dalam proses kelompok dimana mereka selalu mengutarakan pendapatnya dan terlibat aktif dalam aktifitas kelompok.

Ketiga, Kepala Sekolah. Empati pimpinan sekolah terhadap pelaksanaan program menjadi penyemangat para pengajar. Bahkan tidak jarang pimpinan sekolah turun tangan sendiri untuk menjelaskan program-program pengajaran secara langsung.

Keempat, Sarana dan Prasarana. Adanya sarana dan prasarana yang dimiliki oleh MI Tarbiyatul Islamiyah Sumberkerang Gending Probolinggo antara lain kelas multimedia, internet dan lain-lain semakin mendukung terlaksananya pembelajaran PAI dengan menggunakan model pembelajaran Color-Coded Co-op Cards (CoCoCa). "Mampu mengoptimalkan seluruh sarana dan prasarana yang tersedia, sesuai dengan fungsinya dan Memantau keberadaan sarana dan prasarana yang memadai untuk mendukung seluruh layanan pendidikan, baik dari segi jumlah maupun kualitas (Hasan, Wawancara pribadi, 24 Januari 2021).” Hal senada juga dijelaskan Waka Kurikulum bahwa "Sarana prasarana sebagai pendukung dalam membentuk citra lembaga yang baik, dan di lembaga MI Tarbiyatul Islamiyah Sumberkerang Gending Probolinggo sarananya kami rasa masih kurang dan jalan utamanya ialah dengan memanfaatkan sarana yang ada, tentunya dengan adanya integritas pesantren dan lembaga kita bisa memanfaatkan sarana yang ada di pesantren contoh semisal mobil dll, jika sewaktu-waktu dibutuhkan oleh lembaga MI sendiri (Sahri, Wawancara pribadi, 24 Januari 2021)". Sarana dan prasarana pendidikan merupakan fasilitas 
langsung dan tidak langsung yang diperlukan dalam proses belajar mengajar, baik yang bergerak maupun yang tidak bergerak supaya pencapaian tujuan pendidikan dan berjalan dengan lancar, teratur, efektif dan efisien.

Sedangkan faktor penghambat pelaksanaan model pembelajaran Color-Coded Co-op Cards (CoCoCa) dalam pembelajaran PAI di MI Tarbiyatul Islamiyah Sumberkerang Gending Probolinggo antara lain adalah; pertama, Minimnya waktu. Seperti yang diketahui bahwa model pembelajaran kooperatif ini memerlukan banyak waktu dalam pelaksanaannya. "Seperti yang diketahui waktu pelajaran PAI di kelas hanya sebentar, sedangkan sebaliknya penggunaaan metode ini mememerlukan banyak waktu (Sahri, Wawancara pribadi, 24 Januari 2021).”

Kedua, Rendahnya motivasi. Motivasi merupakan salah satu faktor penting yang mempengaruhi belajar siswa. Siswa yang memiliki motivasi cenderung untuk mencurahkan segala kemampuannya untuk menghasilkan hasil belajar yang optimal yang sesuai dengan apa yang diharapkan. "Semakin tinggi motivasi yang dimiliki siswa akan mendorong siswa-siswa belajar lebih giat lagi dan frekuensi belajarnya menjadi semakin meningkat (Hasan, Wawancara pribadi, 24 Januari 2021)." Selain itu, sering tidak adanya mekanisme yang baik dalam proses pembelajaran yang mengakibatkan adanya sikap ketergantungan siswa. Ini memicu tenaga dan pikiran yang ekstra untuk menanganinya. "Guru, terkadang guru juga kurang matang mempersiapkan perangkat-perangkat pembelajaran yang sebenarnya tidak sedikit dan membutuhkan ketelitian (Sahri, Wawancara pribadi, 24 Januari 2021).”

Dengan berbagai macam faktor pendukung maupun penghambat, peneliti menyimpulkan bahwa model pembelajaran Color-Coded Co-op Cards (CoCoCa) sangat efektif untuk diterapkan dalam pembelajaran PAI di MI Tarbiyatul Islamiyah Sumberkerang Gending Probolinggo ataupun materi dan sekolah lainnya. Ini dapat dilihat dari meningkatnya minat belajar siswa yang sebelumnya banyak yang belum paham menjadi lebih memahami dan menguasai materi. Keaktifan siswa dalam proses belajar mengajar juga semakin meningkat, ini terlihat antusiasme mereka yang sangat tinggi untuk selalu berpartisipasi dan memberikan kontribusi terhadap keberhasilan kelompoknya. 
Berdasarkan hasil wawancara dengan para siswa MI Tarbiyatul Islamiyah Sumberkerang Gending Probolinggo, model pembelajaran Color-Coded Co-op Cards $(\mathrm{CoCoCa})$ ini juga sangat bagus dan tepat digunakan dalam pembelajaran materi apapun. Apalagi jika diterapkan dalam pembelajaran Pendidikan Agama Islam ini sangat relevan, karena pembelajaran Pendidikan Agama Islam merupakan pembelajaran yang sangat menjenuhkan. Ketika pembelajaran menerapkan model pembelajaran Color-Coded Co-op Cards (CoCoCa), maka suasana pembelajaran akan berubah menjadi pembelajaran yang sangat menyenangkan. Selain itu, fenomena kerjasama atau gotong royong dalam pembelajaran, terbentuknya sikap dan perilaku yang demokratis serta tumbuhnya produktivitas kegiatan belajar siswa juga tercapai dengan diterapkannya model pembelajaran Color-Coded Co-op Cards (CoCoCa).

Merujuk dari data observasi, wawancara, dan dokumentasi yang telah dilakukan oleh peneliti terkait model pembelajaran Color-Coded Co-op Cards (CoCoCa) di MI Tarbiyatul Islamiyah Sumberkerang Gending Probolinggo, seorang pendidik diharuskan untuk dapat menerapkan model pembelajaran tersebut secara berkesinambungan agar tercapainya tujuan pembelajaran yang diinginkan. Menurut analisis peneliti, dapat disimpulkan bahwa penerapan model pembelajaran Color-Coded Co-op Cards ( $\mathrm{CoCoCa}$ ) dalam meningkatkan minat belajar siswa merupakan kegiatan yang patut untuk tetap diterapkan di MI Tarbiyatul Islamiyah Sumberkerang Gending Probolinggo.

Berdasarkan paparan data dan hasil wawancara, pencapaian hasil belajar siswa dengan menerapkan model pembelajaran Color-Coded Co-op Cards (CoCoCa) mengalami peningkatan yang signifikan. Hal ini ditunjukkan aktivitas siswa dengan persentase sebesar 85\% lebih aktif dalam pembelajaran dibandingkan dengan model pembelajaran yang lain. 


\section{KESIMPULAN}

Berdasarkan hasil penelitan yang telah dilakukan, penerapan model pembelajaran Color-Coded Co-op Cards (CoCoCa) dapat meningkatkan minat belajar siswa di MI Tarbiyatul Islamiyah Sumberkerang Gending Probolinggo. Hal ini dibuktikan dengan antusias dari siswa dalam kegiatan belajar mengajar khususnya pada mata pelajaran PAI. Selain itu, diketahui bahwa adanya faktor pendukung yang meliputi guru, siswa, pimpinan sekolah, sarana dan prasaranan dan faktor penghambat yang meliputi minimnya waktu, rendahnya motivasi dalam penerapan model pembelajaran Color-Coded Co-op Cards (CoCoCa).

Berdasarkan kesimpulan di atas, beberapa saran yang diajukan peneliti yaitu: (1) Bagi Kepala MI Tarbiyatul Islamiyah Sumberkerang Gending Probolinggo. Memberikan rekomendasi bagi para guru agar dapat mengembangkan pelaksanaan sistem pembelajaran yang telah ada melalui penerapan model pembelajaran ColorCoded Co-op Cards ( $\mathrm{CoCoCa}$ ) sebagai model pembelajaran alternatif dalam upaya meningkatkan mutu madrasah yang lebih berkualitas sesuai dengan visi dan misi sekolah yang telah ada. Hasil penelitian ini dapat dijadikan sebagai salah satu sumber masukan untuk kepentingan pengembangan kurikulum dan hasil belajar PAI, sekaligus sebagai motivasi untuk menyediakan sarana dan prasarana sekolah untuk terciptannya pembelajaran yang optimal. (2) Bagi Guru MI Tarbiyatul Islamiyah Sumberkerang Gending Probolinggo. Dengan diterapkannya model pembelajaran Color-Coded Co-op Cards (CoCoCa) dalam poses belajar mengajar diharapkan dapat menghantarkan pada kualitas pembelajaran yang sesuai dengan yang diharapkan serta dapat meningkatkan kreatifitas guru dalam proses belajar mengajar. Selain itu, guru hendaknya lebih terampil dalam mencermati karakteristik siswa dan mampu mengenali kriteria pokok bahasan pada setiap mata pelajaran yang sesuai dengan model pembelajaran Color-Coded Co-op Cards (CoCoCa), sehingga proses pembelajaran lebih efektif, kreatif, inovatif serta menyenangkan pada mata pelajaran PAI dan juga mata pelajaran yang lainnya. (3) Bagi Peneliti lain. Peneliti yang akan mengadakan penelitian sejenis selanjutnya, hasil penelitian ini diharapkan dapat digunakan untuk menambah wawasan tentang penerapan model pembelajaran Color-Coded Co-op Cards $(\mathrm{Co} \mathrm{CoCa})$ dalam pembelajaran di dunia pendidikan. 


\section{DAFTAR PUSAKA}

Baharun, Hasan, Muhammad Mushfi El Iq Bali, Chusnul Muali, and Laili Munawaroh. "Self-Efficacy Sebagai Media Peningkatan Profesionalisme Guru Di Madrasah.” Risalah: Jurnal Pendidikan Dan Studi Islam 6, no. 1 (2020): 244-57.

Bali, Muhammad Mushfi El Iq, and Moh. Fajar Sodik Fadli. "Implementasi NilaiNilai Pendidikan Pesantren Dalam Meningkatkan Ketahanan Mental Santri." PALAPA: Jurnal Studi Keislaman Dan Ilmu Pendidikan 7, no. 1 (May 21, 2019): 115. https://doi.org/10.36088/palapa.v7i1.164.

Bali, Muhammad Mushfi El Iq, Nurul Hidayah, and Siti Maisyaro AL. STRATEGI PEMBELAJARAN Pendidikan Agama Islam. Pustaka Nurja. Vol. 1. Probolinggo: Pustaka Nurja, 2018. https://lp3m.unuja.ac.id/bas/strategi-pembelajaranpendidikan-agama-islam.html.

Bali, Muhammad Mushfi El Iq, and Noer Holilah. "The Role of Foster Caregivers in the Effectiveness of Online Learning in Pesantren." Edukasi Islami: Jurnal Pendidikan Islam 10, no. 1 (2021): 339-62.

Bali, Muhammad Mushfi El Iq, and Itatul Masulah. "Hypnoteaching: Solusi Siswa Learning Disorder." At-Turats: Jurnal Pemikiran Pendidikan Islam 13, no. 1 (2019): 89-103. https://doi.org/10.24260/at-turats.v13i1.1188.

Bali, Muhammad Mushfi El Iq, and Musrifah. "The Problems of Application of Online Learning in the Affective and Psychomotor Domains During the Covid19 Pandemic." Jurnal Pendidikan Agama Islam 17, no. 2 (2020): 137-54. https://doi.org/https://doi.org/10.14421/jpai.2020.172-03.

Bali, Muhammad Mushfi El Iq, and Devi Ruzifah. "Mitigation of Student Deviant Behaviour through Al-Ghazali's Perspective Spiritual Values in the Disruptive Era." Jurnal Pendidikan Progresif 11, no. 1 (2021): 63-76. https://doi.org/10.23960/jpp.v11.i1.20210.

Huda, Miftahul. (2012). Cooperative Learning. Yogyakarta: Pustaka Pelajar.

Islam, Syaiful, Hasan Baharun, Chusnul Muali, Moh Idil Ghufron, Muhammad Mushfi El Iq Bali, Mualim Wijaya, and Ismail Marzuki. "To Boost Students' Motivation and Achievement through Blended Learning." In Journal of Physics: Conference Series, 1114:1-11. Institute of Physics Publishing, 2018. https://doi.org/10.1088/1742-6596/1114/1/012046.

Kagan, Spencer, and Miguel Kagan. Kagan Cooperative Learning. Kagan. San Clemente: Kagan Publishing, 2009.

Khairani. (2013). Psikologi Belajar. Yogyakarta: Aswaja Pressindo.

Lie, Anita. (2010). Mempraktikkan Cooperative Learning di Ruang-Ruang Kelas. Jakarta: Grasindo.

Oktavia, Dewi, Muhammad Mushfi El Iq Bali, Handono Rahman, Umar Umar, Agus Syakroni, and Faizatul Widat. "Exploration of Fine Motor Skills through the Application of Paint." In WESTECH, 1-6. European Alliance for Innovation n.o., 2019. https://doi.org/10.4108/eai.8-12-2018.2284038. 
Rozi, Fathor, Muhammad Mushfi El Iq Bali, Sulton Firdaus, Muallim Wijaya, Rahmatul Aziz Al Mursyidi, Moh Wasil Haqiki, and Zainal Abidin. "Learning Management; Identifying Learning Styles of Language Learners in Madrasah." Proceedings of the International Conference on Industrial Engineering and Operations Management 5, no. August (2020): 3783-90.

Suprijono, Agus. (2012). Cooperative Learning: Teori dan Aplikasi PAIKEM. Yogyakarta: Pustaka Pelajar.

Wahid, Abd Hamid, Najiburrahman, Kholilur Rahman, Faiz, Khodijatul Qodriyah, Hambali, Muhammad Mushfi El Iq Bali, Hasan Baharun, and Chusnul Muali. "Effectiveness of Android-Based Mathematics Learning Media Application on Student Learning Achievement." In Journal of Physics: Conference Series, 1-7. IOP Publishing, 2020. https://doi.org/10.1088/1742-6596/1594/1/012047. 